\title{
Pregnancy Related Screening Test
}

National Cancer Institute

\section{Source}

National Cancer Institute. Pregnancy Related Screening Test. NCI Thesaurus. Code C92721.

Any test performed during pregnancy to assess fetal health and to detect for genetic abnormalities and various disorders. 